IZA DP No. 9283

Short-term Migration and Intergenerational

Persistence of Industry in Rural India

Tushar K. Nandi

Saibal Kar

August 2015

Forschungsinstitut zur Zukunft der Arbeit Institute for the Study of Labor 


\title{
Short-term Migration and Intergenerational Persistence of Industry in Rural India
}

\author{
Tushar K. Nandi \\ Centre for Studies in Social Sciences, Calcutta \\ Saibal Kar \\ Centre for Studies in Social Sciences, Calcutta \\ and IZA
}
Discussion Paper No. 9283
August 2015

\author{
IZA \\ P.O. Box 7240 \\ 53072 Bonn \\ Germany \\ Phone: +49-228-3894-0 \\ Fax: +49-228-3894-180 \\ E-mail: iza@iza.org
}

Any opinions expressed here are those of the author(s) and not those of IZA. Research published in this series may include views on policy, but the institute itself takes no institutional policy positions. The IZA research network is committed to the IZA Guiding Principles of Research Integrity.

The Institute for the Study of Labor (IZA) in Bonn is a local and virtual international research center and a place of communication between science, politics and business. IZA is an independent nonprofit organization supported by Deutsche Post Foundation. The center is associated with the University of Bonn and offers a stimulating research environment through its international network, workshops and conferences, data service, project support, research visits and doctoral program. IZA engages in (i) original and internationally competitive research in all fields of labor economics, (ii) development of policy concepts, and (iii) dissemination of research results and concepts to the interested public.

IZA Discussion Papers often represent preliminary work and are circulated to encourage discussion. Citation of such a paper should account for its provisional character. A revised version may be available directly from the author. 
IZA Discussion Paper No. 9283

August 2015

\section{ABSTRACT \\ Short-term Migration and Intergenerational Persistence of Industry in Rural India}

One of the well-known barriers to development is persistence of disadvantage among communities. The lack of occupational and therefore upward social mobility continues to restrain households from achieving socially desirable outcomes. This paper studies the effect of short-term internal migration experience on the intergenerational persistence of industry upon a migrant's return to native place. We develop an occupational choice model of a return migrant to study the relationship between the migrant's savings, skill or any other productive asset accumulation during migration and the decision to work upon return, in the industry where his/her father is employed. Using data from a nationally representative sample survey, we find that short-term migration by males reduces the probability of intergenerational persistence by $20 \%$ in rural India. Migration to urban areas, work experience in a different industry and higher frequency of migration reduce the return migrant's chance of being employed in the industry where his father is employed. The results suggest that skill formation during migration can play a key role in reducing labour market inequality by weakening the strength of intergenerational transmission of disadvantages.

JEL Classification: J24, O12, O18

Keywords: migration, occupation, industry, household survey, rural India

Corresponding author:

Saibal Kar

Centre for Studies in Social Sciences, Calcutta

R-1, B. P. Township

Kolkata 700094

India

E-mail: Kar: saibal@cssscal.org 


\section{Introduction}

Migration flow from the developing countries has increased over the last decades. The international migration flow and its effects, particularly through the channel of remittance, have received considerable attention in economic literature ${ }^{1}$. However, much less has been written about internal migration, though its magnitude is much higher than international migration². India, known to be one of the largest sources of global migration and recipients of remittance, had 326 million internal migrants in 2007-08 (NSSO, 2010). This exceeds by far the estimates of Indian emigrants (11.4 million) (World Bank, 2011).

Internal migration often takes the form of seasonal or circular movements between rural and urban areas. This opens up the possibility of transmission of human, social and financial capital from urban to rural areas. The occupational choice of return migrants with international experience has been studied extensively (see Martin and Radu, 2012; Piracha and Wadean, 2010; Wahba and Zenou, 2012). Among the few studies that focused on the occupational choice of internal return migrants, Demurger and Xu (2011) studied the self-employment decision of return migrants in China. They found that both return savings and frequency of job changes are associated with higher probability that return migrants become self-employed.

This paper studies the role internal migration plays in the intergenerational mobility across industries in India. The country has witnessed rapid economic growth in the last few decades. However, there is growing concern that this economic growth has been accompanied by rising inequality. Recently, the role of intergenerational transmission of advantages or disadvantages in inequality in labour market outcomes has come to the forefront of the debate on equality of opportunities $^{3}$. In this paper, we study whether internal migration experience plays any role in

\footnotetext{
${ }^{1}$ See Amuedo-Dorantes and Pozo (2006), Cox-Edwards and Rodríguez-Oreggia (2009) and Gibson et al. (2011).

${ }^{2}$ UNDP (2009) reports that the number of internal migrants is four times that of international migrants.

${ }^{3}$ See Majumder (2010), Dahan and Gaviria (2001), and Nandi (2013).
} 
the intergenerational persistence of industry. Does the skill, capital or any other productive asset accumulation during migration facilitate intergenerational mobility across industries? More precisely, is the son of a farmer who has had a short-term migration spell, less likely to work in the agricultural sector upon his return? The answer to these questions has important policy implications. If internal migration is able to break the intergenerational chain of transmission of fortune or misfortune, a policy to facilitate internal migration can reduce social inequality by reshuffling the skill and capital that determine occupational choice.

In this paper we provide a theoretical framework that models the link between skill/capital accumulation during migration and occupation choice upon return. We use data from a nationally representative sample survey to estimate the effect of short-term internal migration on the intergenerational persistence. Unlike many other studies, our data set provides information on the migrant's characteristics, destination and industry of employment during migration. We use this information to examine the heterogeneity in the effect of short-term migration on persistence. We find that short-term migration by a son reduces the probability that upon return he works in the industry where his father is employed, by $20 \%$. Our results show that migration to urban areas, more frequent migration spells and work experience in a different sector reduce the chance of intergenerational persistence.

The rest of the paper is organised as follows. The second section provides a simple model of occupation choice of a return migrant. Section three and four present the data and estimation results, respectively. Section five presents the heterogeneity, in terms of migrant's characteristics, in the effect of short-term migration on persistence. The last section concludes the paper and provides policy recommendations. 


\section{A model of occupational choice of return migrant}

We use a simple model to capture the essential features of temporary migration and occupational choice at the source. Temporary migration in this framework suggests that the worker returns to his/her origin, and subsequently chooses an occupation that belongs either to the same industry or sector where his/her parent(s) worked, or in another sector unrelated to the parental profession. In this model, we assume that the individual migrates from one region of the country to another - a common feature in countries like China, India, Russia or even the United States that are spread out sufficiently to accommodate various forms of economic activities, socio-cultural diversities and regional disparities. The question we are addressing is straightforward. What are the factors that drive a representative agent (temporary migrant), as in our model, to choose the parents' occupation on return? In order to define the scope of such choice, we argue that if the occupation is the same as that of the parents, it should be considered as intergenerational persistence of occupation. Stated alternatively, the occupational persistence across generations breaks down if the agent chooses an occupation that is functionally unrelated to that of his/her immediate predecessor. The problem lends itself to a treatment of the choice of occupation distributed over two subsequent time periods, which we denote as ' $t$ ' and ' $1-t$ ', where the total time available to the agent over a lifetime is normalized to 1 .

The individual is born with no capital or bond holdings, and supplies one unit of labour inelastically at every period. We do not add any restrictions and assumptions on the distribution of income earned during the period of migration and post-return. In earlier models (see, Katz and Stark, 1987; Djajic and Milbourne, 1988; Mesnard, 2000; Beladi and Kar, 2015; etc) the migrant's income is treated as stochastic. The earlier models also apply a discount factor to his/her income, as a migrant since staying away from home leads to disutility. The disutility 
discussed in such cross-border migration models emanates mainly from socio-cultural distances, which includes, but is not limited to staying away from family, localized food habits, etc. In our model the migration from one region to another may also open up issues of discounting income and consumption as a migrant, but presumably the degree of heterogeneity across regions of the same country may not be crucial as in previous models. Therefore, we dispense with the discounting factor.

We assume that the worker stays away from home as a migrant for ' $t$ ' periods and then returns home to choose an occupation to work for over ' $1-t$ ' periods until life ends. The worker is riskaverse, cares about his/her own consumption only and is an expected utility maximizer. Thus, we assume that the worker consumes $C_{M}$ as a migrant and 'retains' $S$ out of the total income earned during migration $\left(W_{M}\right)$. The additive term ' $S$ ' can be interpreted in several ways. It may be construed as savings, or as skill acquired during the period as migrant, or even as investments made in assets. Treating $W_{M}$ as the numeraire, one can further interpret $0<S<1$, as the probability with which the migrant adopts the parental occupation or chooses an alternative on return. In fact, we show that $S$ is the crucial determinant of the occupational choice in our model. In addition, if, moving away from a representative agent structure, we consider a mass of identical individuals instead, then the critical value of $S$ should serve as a separating equilibrium between who chooses the parental occupation and who the alternative, ex post. In other words, one can consider that the workers are distributed uniformly on a scale of skill accumulation or savings, such that, $S \in[0,1]$. If the critical value of $S$ (given that it exists and is unique) is obtained from the decision problem we discuss next, then workers with $S$ greater than the critical value $\left(S^{*}\right)$ choose an alternative occupation, while those with $S<\left(S^{*}\right)$ stay in the parental occupation. It should mean that the level of skill/savings accumulated as a migrant regardless of the occupation he/she engages in, is decisive for future action. Presently, 
we will assume that $0<S<1$ without further restrictions on the distribution of $S$. The worker does not borrow and does not lend at any point, and he is not finance constrained.

The worker faces a von-Neumann-Morgenstern type direct utility function with constant absolute risk aversion (CARA), $U=-\exp \left(-X_{j}\right), U^{\prime}>0, U^{\prime \prime}<0$, where $X_{j}$ is the level of consumption for activity $j$. Thus, as a migrant $(M)$ over $t$ periods the worker consumes $C_{M}$ and retains $S$. The consumption as a migrant is random and there is an additive uncertainty ( $0<\beta<1$ ), such that,

$$
\begin{aligned}
E U(M) & =-t \iint \exp \left(-C_{M}-S+\beta\right) d S d \beta \\
\text { or, } \quad & E U(M)=\exp \left(-C_{M}-S+\beta\right) . t
\end{aligned}
$$

Next, consider the occupational choice facing the worker on return.

$$
E U(R)=-(1-t) \int \exp \left[-(1-S) C_{P}-S\left(C_{A}\right)\right] d S
$$

Equation (3) suggests that over (1-t) periods, the individual either joins a new occupation that allows him/her to consume $\left(C_{A}\right)$ with probability $S$ or stays in the parental occupation with probability (1-S) and consumes $\left(C_{P}\right)$.

This leads to,

$$
E U(R)=-\frac{(1-t) \exp \left[-(1-S) C_{P}-S\left(C_{A}\right)\right]}{C_{P}-C_{A}}
$$

Considering $\left(C_{M}\right)$ as the numeraire, we can re-write equations (2) and (4) as:

$$
E U(M)=\exp (-1-S+\beta) \cdot t
$$


and, $\quad E U(R)=-\frac{(1-t) \exp \left[-(1-S) \tilde{C}_{P}-S\left(\tilde{C}_{A}\right)\right]}{\tilde{C}_{P}-\widetilde{C}_{A}}$

where $\tilde{C}_{j}$ are reformulated consumption levels obtained from the $\mathrm{j}^{\text {th }}$ occupation, $j=P, A$.

At the margin, an individual is indifferent between the expected utility to stay as a migrant or return home and earn an expected income by either joining the parental occupation or by choosing an alternative. Thus, equating (5) and (6), we solve for $S^{*}$, as the probability of a migrant worker to choose an alternative occupation on return.

$$
S^{*}=\frac{\widetilde{C}_{P}+\beta+\ln \left[\frac{t\left(\widetilde{C}_{A}-\tilde{C}_{P}\right)}{1-t}\right]-1}{1+\widetilde{C}_{P}-\widetilde{C}_{A}}
$$

Over appropriate values of the parameters of the model, one can show that $S^{*}$ exists and is unique within $[0,1] .{ }^{4}$ Intuitively, one can argue that $E U(M)>E U(R)$ over a considerable range of $S$, such that all individuals distributed with $S<S^{*}$ shall be employed in the parental profession, while those with $S>S^{*}$ shall be in an alternative occupation. It is possible that the payoff from the alternative occupation is a function of $S$, as one would expect with selfemployment behaviour aided by savings accumulated as a migrant.

Interestingly, from (7) it follows that the duration of migration has a positive impact on $S^{*}$. This means that the longer the worker stays away from home, the more likely it is that he/she joins an alternative occupation if the consumption from parental occupation falls short of that obtained from the alternative occupation. In other words,

\footnotetext{
${ }^{4}$ The program and numerical solutions are available on request.
} 


$$
\frac{\delta S^{*}}{\delta t}=\frac{1}{(1-t) t\left(1+\tilde{C}_{P}-\tilde{C}_{A}\right)}<0, \text { iff } 1<\left(\tilde{C}_{A}-\tilde{C}_{P}\right)
$$

It is easy to check from (8) that $\underset{t \rightarrow 0}{\operatorname{lt}} \frac{\delta S^{*}}{\delta t} \rightarrow \infty$, which implies that if the person spends no time away from home, the probability of choosing the parental profession is extremely high (since for all $S<S^{*}$, individuals stay in parental occupation). Alternatively, as the person stays longer as a migrant, $S^{*}$ becomes positive finite and implies that the intergeneration persistence in the same industry gradually withers away.

In other words, condition (8) suggests that longer duration of migration raises the probability of joining the alternative occupation if the condition holds. This forms an empirically testable proposition. In our empirical analysis, we attempt to test the effect of migration and its variation in terms of destination, industry of employment during migration and numbers of migration spell on the intergenerational persistence of occupation.

\section{Data and descriptive statistics}

We use data from the $64^{\text {th }}$ round survey on "Employment, Unemployment and Migration Particulars”, carried out by National Sample Survey Office, India during July 2007 to June 2008. The survey collects information from a nationally representative sample of households covering all the states of India. On the issue of migration, the survey collects information on both long-term and short-term migration. Short-term migration is defined as a migration spell between 1 to 6 months. Our analysis is based on male individuals who are 18-30 years old and live in rural areas.

Table 1 gives the descriptive statistics of the sample used for the analysis. The first column of numbers reports the intergenerational persistence, age, marital status, education, caste and 
religion of the full sample. The next two columns provide the same information for individuals with and without short-term migration experience, respectively.

Table 1: Descriptive statistics

\begin{tabular}{|c|c|c|c|}
\hline & All & Migrants & Non-migrants \\
\hline & \multicolumn{3}{|c|}{ Sample proportions } \\
\hline Intergenerational persistence & 0.70 & 0.61 & 0.72 \\
\hline Short-term migration & 0.19 & & \\
\hline Age $\S$ & $22.79(4.07)$ & $22.38(3.89)$ & $22.88(4.11)$ \\
\hline Married & 0.38 & 0.38 & 0.38 \\
\hline \multicolumn{4}{|l|}{ Education } \\
\hline No formal education & 0.23 & 0.29 & 0.22 \\
\hline Primary & 0.21 & 0.23 & 0.20 \\
\hline Secondary & 0.44 & 0.39 & 0.45 \\
\hline Higher secondary & 0.07 & 0.05 & 0.08 \\
\hline College or more & 0.05 & 0.04 & 0.05 \\
\hline Scheduled Tribe & 0.18 & 0.16 & 0.19 \\
\hline Scheduled Caste & 0.19 & 0.23 & 0.18 \\
\hline Other Backward Caste & 0.40 & 0.43 & 0.40 \\
\hline General Caste & 0.23 & 0.19 & 0.24 \\
\hline Hindu & 0.77 & 0.81 & 0.77 \\
\hline Muslim & 0.12 & 0.14 & 0.12 \\
\hline Christian & 0.06 & 0.03 & 0.07 \\
\hline Other religion & 0.04 & 0.02 & 0.05 \\
\hline Number of observations & 21856 & 4171 & 17685 \\
\hline$\S$ Mean value (standard deviatic & & & \\
\hline
\end{tabular}

The table shows that $70 \%$ individuals in our sample work in the industry where their fathers are also employed ${ }^{5}$. The persistence is $61 \%$ among individuals with short-term migration experience, compared to $72 \%$ among individuals without short-term migration experience. In terms of age and marital status, short-term migrants and non-migrants are very similar. Education is slightly higher among non-migrants. Among the migrants, there are 29\% individuals without any formal education whereas there are 22\% among non-migrants. However, there are $39 \%$ with secondary education among migrants compared to $45 \%$ among

\footnotetext{
${ }^{5}$ Persistence is defined as father and son being employed in an industry with same two digit industrial classification.
} 
non-migrants. We also observe that the percentage of individuals with higher secondary or more education is slightly high among non-migrants. There are more individuals from Scheduled Castes and Other Backward Castes among the migrants than from Scheduled Tribes (ST) and general caste. Hindus and Muslims have more short-term migration experience than that of Christians and other religions.

Further descriptive analysis shows that persistence is the highest (76\%) when the father is employed in the agricultural sector, followed by the construction sector (62\%). Low level of persistence is observed when the father is employed in public administration (9\%) and education industry (14\%). The persistence in agriculture is $64 \%$ for migrant sample and $79 \%$ for non-migrant sample. However, the persistence in construction sector differs significantly between migrants (76\%) and non-migrants (57\%). It seems that the large part of change in persistence for migration happens through shifts between agriculture and construction sector. There is also considerable variation among the migrants in terms of destination, frequency of migration and industry experience during migration. Among the migrants $78 \%$ moved to urban areas for employment and $21 \%$ to another rural area. There are $43 \%$ migrants with one migration spell, $28 \%$ with two spells, $13 \%$ with three, and the rest with more than three spells in a year. The majority (82\%) of the migrants worked in an industry during migration spell that is different from the industry where their fathers work in their native place.

\section{Estimation results}

In this section we use an econometric model to estimate the effect of short-term migration on the intergenerational persistence of industry. The dependent variable takes value 1 if father and son work in same industry, 0 otherwise. The main explanatory variable is a dummy variable for the son's short-term migration for employment during the last year. The model includes variables for age, marital status, and education of son, parental education, household 
characteristics like land ownership, caste and religion. Since local economy is an important predictor of job opportunities, hence of intergenerational persistence of industry, the model also includes district fixed effects.

Estimation of the model raises issues of sample selection and endogeneity. In the model described above the migration dummy variable is treated as exogenous. It is reasonable to assume that migrants are a self-selected group in terms of unobservable factors like motivation and risk aversion. If migrants are less risk averse than non-migrants, they may be more likely to engage in works that their fathers do not do. Under this rationale, the migration decision is endogenous to the decision to work, upon return, in the industry where the father is employed. It is also possible that short-term internal migration decision and occupational choice decision upon return are simultaneous. All these issues can be described as omitted variable problem. A variety of approaches are employed in literature to address the issues of sample selection and endogeneity. Demurger and Xu (2011) use a recursive bivariate probit model to estimate the effect of return migration on self-employment decision in rural China. Carletto and Kilic (2011) apply the instrumental variable approach to estimate the effect of migration experience on occupational mobility in Albania.

We estimate both a recursive bivariate probit model where migration decision is modelled separately and a simple probit model. We find similar results. In the following, we report the estimates from the probit model and discuss the results of recursive bivariate probit model as robustness check.

In order to address potential selection bias, we have considered a probit model and instrumental variable approach. In the process, we have taken the district fixed effects for 580 districts all over the country. Our results do accommodate these many intercepts. The sample selection bias should not pose a serious problem for these results because the district 
fixed effects with district-specific macro indicators capture the origin related issues between migrants and non-migrants. 
Table 2: Estimates from probit model of intergenerational persistence

\begin{tabular}{|c|c|c|c|c|c|c|c|c|c|}
\hline & \multicolumn{3}{|c|}{ (i) } & \multicolumn{3}{|c|}{ (ii) } & \multicolumn{3}{|c|}{ (iii) } \\
\hline & Coeffcient & & S. Error & Coeffcient & & S. Error & Coeffcient & & S. Error \\
\hline Short-term migration & -0.352 & *** & 0.027 & -0.352 & $* * *$ & 0.028 & -0.335 & $* * *$ & 0.028 \\
\hline Age & -0.006 & * & 0.003 & -0.006 & * & 0.004 & -0.009 & ** & 0.004 \\
\hline Married & 0.098 & $* * *$ & 0.026 & 0.090 & $* * *$ & 0.027 & 0.075 & $* * *$ & 0.027 \\
\hline \multicolumn{10}{|c|}{ Education (no fomal education omitted) } \\
\hline Primary & -0.131 & $* * *$ & 0.033 & -0.131 & $* * *$ & 0.034 & -0.152 & $* * *$ & 0.035 \\
\hline Secondary & -0.273 & *** & 0.029 & -0.233 & $* * *$ & 0.031 & -0.273 & $* * *$ & 0.032 \\
\hline Higher secondary & -0.456 & $* * *$ & 0.044 & -0.352 & $* * *$ & 0.047 & -0.420 & $* * *$ & 0.047 \\
\hline College or more & -0.974 & $* * *$ & 0.049 & -0.810 & $* * *$ & 0.053 & -0.899 & $* * *$ & 0.054 \\
\hline \multicolumn{10}{|c|}{ Father's education (no formal education omitted) } \\
\hline Primary & & & & -0.042 & & 0.032 & -0.061 & * & 0.032 \\
\hline Secondary & & & & -0.177 & $* * *$ & 0.032 & -0.207 & $* * *$ & 0.032 \\
\hline Higher secondary & & & & -0.463 & $* * *$ & 0.075 & -0.510 & $* * *$ & 0.076 \\
\hline College or more & & & & -0.628 & *** & 0.086 & -0.701 & $* * *$ & 0.086 \\
\hline \multicolumn{10}{|c|}{ Mother's education (no formal education omitted) } \\
\hline Primary & & & & 0.017 & & 0.040 & 0.011 & & 0.040 \\
\hline Secondary & & & & -0.025 & & 0.049 & -0.017 & & 0.049 \\
\hline Higher secondary & & & & 0.056 & & 0.199 & 0.089 & & 0.201 \\
\hline College or more & & & & -0.057 & & 0.242 & -0.016 & & 0.245 \\
\hline \multicolumn{10}{|c|}{ Land owned (less than 0.005 hectare omitted) } \\
\hline 0.005 to 0.01 hectare & & & & & & & 0.000 & & 0.048 \\
\hline 0.01 to 0.2 hectare & & & & & & & -0.035 & & 0.049 \\
\hline 0.2 to 0.4 hectare & & & & & & & -0.021 & & 0.049 \\
\hline 0.4 to 1 hectare & & & & & & & 0.203 & $* * *$ & 0.046 \\
\hline 1 to 2 hectare & & & & & & & 0.377 & $* * *$ & 0.048 \\
\hline more than 2 hectare & & & & & & & 0.555 & $* * *$ & 0.054 \\
\hline \multicolumn{10}{|c|}{ Caste (General Caste omitted) } \\
\hline Scheduled Tribe & 0.169 & $* * *$ & 0.048 & 0.122 & $* *$ & 0.050 & 0.176 & $* * *$ & 0.051 \\
\hline Scheduled Caste & -0.181 & $* * *$ & 0.035 & -0.225 & $* * *$ & 0.036 & -0.091 & $* *$ & 0.038 \\
\hline Other Backward Caste & -0.010 & & 0.030 & -0.042 & & 0.031 & 0.010 & & 0.032 \\
\hline \multicolumn{10}{|l|}{ Religion (Hindu omitted) } \\
\hline Muslim & -0.286 & *** & 0.039 & -0.303 & $* * *$ & 0.040 & -0.243 & $* * *$ & 0.040 \\
\hline Christian & 0.040 & & 0.095 & 0.037 & & 0.100 & 0.021 & & 0.101 \\
\hline Other religion & 0.128 & $*$ & 0.077 & 0.131 & & 0.081 & 0.108 & & 0.081 \\
\hline Log likelihood & \multicolumn{3}{|c|}{-10531.20} & \multicolumn{3}{|r|}{-9960.37} & \multicolumn{3}{|r|}{-9824.73} \\
\hline Number of observations & & & 19,618 & & & 18,565 & & & 18,549 \\
\hline
\end{tabular}

Three different specifications of the probit model are estimated, progressively incorporating additional variables. All of them include control for caste, religion and district fixed effects. Table 2 presents the estimation results. The first specification (i) has 'son' related variables short-term migration, age, marital status and education in addition to the fixed effects. The estimated coefficient of the variable for short-term migration is negative and highly significant. In terms of marginal effect, the result shows that short-term migration experience of the son reduces his chance of being employed on return in the industry where his father works, by $20 \%$. Age appears to be negatively associated with intergenerational persistence, though the 
coefficient is marginally significant. Married individuals are more likely to be employed in the industry where their fathers work. Estimates of the variables for education show that higher the level of educational attainment, lower is the probability that a father-son pair work in same industry. Looking at the estimates for caste variables, we find that intergenerational persistence is higher among Scheduled Tribes and lower among Scheduled Castes, compared to General Caste. There is also evidence that intergenerational persistence of industry is lower among Muslims than Hindus.

The next specification (ii) incorporates parental education. The estimated coefficient of the variable for short-term migration remains unchanged. Again, the short-term migration experience of the son reduces the chance that the father-son pair are employed in same industry by $20 \%$. The father's education attainment above primary level is associated with lower probability of intergenerational persistence of industry. We find that mother's educational attainment does not exert significant effects on the transmission of industry from father to son. Estimates of other variables and their level of significance are similar to those of specification (i).

In specification (iii) of the probit model, variables for land ownership are included. The coefficient of short-term migration reduces slightly. In terms of marginal effect, the estimate indicates that short-term migration experience reduces the intergenerational persistence of industry by $19 \%$. The estimates of the land ownership variables show that land size of 0.4 hectare or more is associated with higher probability of intergenerational persistence. The persistence with higher land size is driven by the fact that $89 \%$ of fathers with 0.4 hectare or more land are working in the agricultural sector, whereas only $56 \%$ with less land work in agriculture. Estimates of other variables maintain the same sign and significance as in the previous specifications. Age is negatively, and being married positively associated with intergenerational persistence. The higher the educational attainment of the son, lower is his 
chance of being employed in the industry where his father works. The father's education is negatively associated with intergenerational persistence. In all the specifications, the mother's education is insignificant. Intergenerational persistence is higher (lower) among Scheduled Tribes (Scheduled Castes) compared to general caste individuals. Muslim individuals, in comparison to Hindus, are less likely to work in the industry where their fathers work.

As mentioned earlier, we also estimate a recursive bivariate probit model where, in addition to outcome equation of the probit model, a second equation estimates the migration decision. The covariance between the error terms of these two equations is considered to be a measure of the strength of unobservable factors in determining both intergenerational persistence and short-term migration. The identification of parameters in a recursive model depends on the inclusion of valid instruments in the migration equation. Often, the share of migrants in the locality, gauging the migration network, is used as an instrument (Binzel and Assad, 2011; Mendola and Carletto, 2012). We use the share of migrants among male adults in a village hamlet as an instrumental variable in migration decision equation. The equation also incorporates all the variables included in the equation for intergenerational persistence. We find a negative and significant effect of migration on intergenerational persistence. However, the covariance between error terms of the equations is not statistically significant from zero. Further exploration reveals that if we include additional variables, as in the probit model, the significance of covariance changes. It loses its significance when land variables are incorporated in both the equations. This suggests that after including all the variables, the residuals retain vary little to be determining factors in migration and same industry employment decisions. In India, often landless, less educated individuals from SC, ST or OBC engage in short-term employment related migration. Once these factors are accounted for in our model, much of the omitted variable problem disappears. 
The estimation results reported in Table 2 give robust evidence that short-term migration negatively affects intergenerational persistence of industry. Now we turn to the identification of channels through which the migration affects intergenerational persistence. In the next set of estimations, we use the specification (iii) of Table 2 and focus on three possible channels that may generate the negative effect.

The first channel concerns the destination of short-term migration. The wage differential between different migration destinations plays the key role in destination choice. However, other aspects of destination - like diversity of job opportunities, connection to networks and skill acquisition - have important implications for intergenerational persistence of the return migrant. An individual migrating from a rural area to another rural area will be less exposed to these aspects than an individual who migrates from a rural area to an urban area. In the full specification of probit model, we introduce two variables, dividing migration into rural to rural and rural to urban migration. Estimation result is presented in specification (i) of Table 3. Though the model incorporates the full set of variables, marginal effect of the main variables are reported for the sake of space. It shows that short-term migration from rural to rural areas reduces the intergenerational persistence by $7 \%$. However, the effect of rural to urban migration is $23 \%$, more than three times the effect of rural to rural migration. 
Table 3: Channels through which short-term migration affects intergenerational persistence

\begin{tabular}{|c|c|c|c|c|c|c|c|c|c|}
\hline & \multicolumn{3}{|c|}{ (i) } & \multicolumn{3}{|c|}{ (ii) } & \multicolumn{3}{|c|}{ (iii) } \\
\hline & Marginal effect & & S. Error & Marginal effect & & S. Error & Marginal effect & & S. Error \\
\hline \multicolumn{10}{|l|}{ Destination } \\
\hline Rural to rural & -0.072 & $* *$ & 0.032 & & & & & & \\
\hline Rural to urban & -0.233 & $* * *$ & 0.021 & & & & & & \\
\hline Number of migration spells & & & & $-0.109 *$ & *** & 0.010 & & & \\
\hline Number of migration spells squared & & & & $0.009 *$ & *** & 0.002 & & & \\
\hline \multicolumn{10}{|c|}{ Work experince during migration spell } \\
\hline In same industry as father & & & & & & & 0.372 & $* * *$ & 0.014 \\
\hline In different industry from father & & & & & & & -0.377 & $* * *$ & 0.023 \\
\hline Log likelihood & & & -9816.007 & & & -9812.154 & & & -9532.132 \\
\hline Number of observations & & & 18,549 & & & 18,549 & & & 18,549 \\
\hline
\end{tabular}

The second channel concerns the number of migration spells a migrant had in the previous year. A migration spell is defined as at least 15 days away from home for employment. Conceptually, the longer the migration spell, the more is the possibility of acquiring skill. Work experience during a migration spell affects skill acquisition that makes an individual less reliant on the skills transmitted from previous generation, hence reducing the chance of intergenerational persistence. Longer migration spell may also lead to savings that upon return forms the capital for self-employment. In either case, work experience during migration is likely to have a bearing on intergenerational persistence. However, we don't have information on the length of migration spell. It is reasonable to assume that the number of migration spells is positively correlated with total length of migration period. The higher the number of spells, the higher will be the amount of skill acquired during migration, and hence the lower the probability if intergenerational persistence. However, too many spells in a year may lead to less skill formation as the length of each spell is likely to be small. Migration to different destinations in each spell may further affect skill formation during migration. We do not have information on destination in each spell. We assume that circular migration may be motivated by employment opportunities spread over seasons in different destinations. In order to estimate 
the possible non-linear effect of the number of migration spells on intergenerational persistence, we use both the number of migration spells and its squared term in the model. Estimation results are presented in specification (ii) of Table 3. It shows that a migration spell reduces the probability of intergenerational persistence by $10 \%$. However, an additional spell also increases the probability by $1 \%$. The results suggest that if an individual has ten migration spells in a year, his probability of being employed in the industry where his father works is not different from those who do not migrate.

As for the third channel, we focus on the effect of the nature of work experience during migration on the return migrant's probability of working in the industry there his father is employed. In particular, we examine whether an individual's work experience during migration spell in an industry different from where his father is employed affects intergenerational persistence when the migrant returns. On one hand, an individual's work experience in a different industry during migration leads to acquisition of a set of skills that is not possessed by his father. This skill difference may lead to lower probability that father and son are employed in the same industry. On the other hand, an individual's work in the same industry (as father) during migration may augment the skills transmitted from father, increasing the possibility that the father-son pair works in the same industry when the migrant returns home. We use two dummy variables for same and different industry experience during migration spell in specification (iii). The estimation results confirm our hypothesis that work experience in same industry as father increases and work experience in different industry decreases intergenerational persistence. More precisely, those who work in the same industry during migration spell are 37\% more likely and those who work in different industry are 38\% less likely to work, upon return, in the industry where the father works than those who don't migrate. 


\section{Conclusion}

This paper studies the effect of short-term internal migration on the intergenerational persistence of industry upon return to native village. We use a simple theoretical framework that highlights the role of skill, saving or any other productive asset acquired during migration spell in determining the choice between working in the industry where father is employed visà-vis any other industry. We use data from a nationally representative sample survey from India to empirically estimate the effect of migration on intergenerational persistence of industry. The empirical analysis shows that short-term migration reduces the probability that an individual, upon return, works in the industry where his father is engaged.

Using considerable variation among migrants in the destination, number of migration spells and industry experience, we also shed light on the channels through which migration affects intergenerational persistence. The results point to the role of skill acquisition during migration in determining the occupation on return from migration. Particularly, migration to urban areas as opposed to another rural area, for a long duration, with experience to work in an industry different from where the father is employed in the native place, reduces the probability that father-son pair is employed in the same industry. The results have important policy implications. Intergenerational transmission of advantage or disadvantages perpetuates economic inequality. Short-term internal migration can push people out of the trap that gives persistence. Indeed, short-term migration with the possibility of skill formation can reshuffle the distribution of unequal opportunities in the labour market. 


\section{References}

Amuedo-Dorantes, C. and Pozo, S. (2006). Migration, remittances, and male and female employment patterns. The American Economic Review, Vol. 96(2), pp. 222-226.

Beladi, H. and Kar, S. (2015) Skilled and Unskilled Immigrants and Entrepreneurship in a Developed Country, forthcoming, Review of Development Economics.

Binzel, C. and Assaad, R. (2011). Egyptial men working abroad: Labour supply responses by the women left behind, Labour Economics, Vol. 18, pp. S98-S114.

Carletto, C. and Kilic, T. (2011). Moving up the ladder? The impact of migration experience on occupational mobility in Albania. Journal of Development Studies, Vol. 47(6).

Cox-Edwards, A. and Rodríguez-Oreggia, E (2009). Remittances and Labor Force Participation in Mexico: An Analysis Using Propensity Score Matching. World Development, Vol. 37(5), pp. 1004-1014.

Dahan, M. and Gaviria, A. (2001). Sibling correlations and intergenerational mobility in Latin America, Economic Development and Cultural Change, Vol. 49(3).

Demurger, S. and $\mathrm{Xu}, \mathrm{H}$. (2011). Return migration: The rise of new entrepreneurs in rural China. World Development Vol. 39(10) pp. 1847-1861.

Djajic, S. and Milbourne, R. (1988), A General Equilibrium Model of Guest-Worker Migration: A Source-Country Perspective, Journal of International Economics, 25, 335-351.

Gibson, J., McKenzie, D. and Stillman, S. (2011). The impacts of international migration on remaining household members: Omnibus results from a migration lottery program. Review of Economics and Statistics.

Katz, E. and Stark, O. (1987). International Migration Under Asymmetric information, The Economic Journal, Vol. 97( 387), pp. 718-726.

Martin, R. and Radu, D. (2012). Return Migration: The Experience of Eastern Europe, International Migration, Vol 50(6), pp. 109-128.

Majumder, R. (2010). Intergenerational mobility in educational and occupational attainment: A comparative study of social classes in India, Margin: The Journal of Applied Economic Research.

Mendola, M. and Carletto, C. (2012) Migration and gender differences in the home labour market: Evidence from Albania, Labour Economics, Vol. 19, pp. 870-880.

Mesnard, A. (2000), Temporary Migration and Capital Market Imperfections", mimeo, ARQADE, University of Toulouse. 
Nandi, T. K. (2013). Intergenerational persistence of Industry in India, CTRPFP Working Paper No. 4. CSSS, Calcutta.

NSSO (2010). Migration in India, Ministry of Statistics and Program Implementation, Govt. of India.

Piracha, M., \& Vadean, F. (2010). Return migration and occupational choice: Evidence from Albania. World Development, Vol 38(8), pp. 1141-1155.

UNDP (2009). Human Development Report, United Nations Development Program.

Wahba, J. and Zenou, Y. (2012). Out of sight, out of mind: Migration, entrepreneurship and social capital, Regional Science and Urban Economics, Vol. 42 pp. 890-903.

World Bank (2011). Migration and remittances: Fact book. World Bank, Washington DC. 